\title{
Stakeholders no contexto das smart cities
}

\author{
Stakeholders in the context of smart cities
}

Grupos de interés no contexto das smart cities

Recebido: 12/01/2021 | Revisado: 14/01/2021 | Aceito: 19/01/2021 | Publicado: 24/01/2021

\author{
Jefferson Cirne da Costa \\ ORCID: https://orcid.org/0000-0001-5401-7068 \\ Universidade Nove de Julho, Brasil \\ E-mail: jeffersonccosta28@gmail.com \\ José Storópoli \\ ORCID: https://orcid.org/0000-0002-0559-5176 \\ Universidade Nove de Julho, Brasil \\ E-mail: josees@uni9.pro.br
}

\begin{abstract}
Resumo
Em 2050, 70\% da população mundial viverá em cidades, pressionando as gestões a tornarem-se inteligentes e os stakeholders ganham relevância e interesse enquanto objeto de estudo, passando a disputar o protagonismo nestes territórios. Não identificamos estudos que reconheçam estes stakeholders nas cidades inteligentes. O objetivo foi identificá-los, bem como os seus atributos e a sua saliência. Realizamos uma revisão sistemática da literatura e obtivemos 82 documentos finais. Como resultado, a sociedade civil foi o stakeholder mais citado, seguido pelas indústrias/companhias, na sequência pelos governos e, por último, pela academia/universidades. Os resultados, tanto por região geográfica de estudo quanto pela formação acadêmica dos autores, remetem ao mesmo resultado. Não identificamos menção à saliência e aos atributos dos stakeholders das smart cities, indicando lacuna científica a ser futuramente estudada. Ensino e pesquisa foi o segmento menos significativo entre os stakeholders, indicando a necessidade de inserção deste grupo como protagonistas ativos neste processo. Concluimos que a sociedade civil carece de ser efetivamente envolvida nestas iniciativas de smart cities, afinal de contas, seriam estes os principais acionistas destas cidades.
\end{abstract}

Palavras-chave: Stakeholders; Cidades inteligentes; Hélice quádrupla; Revisão sistemática.

\begin{abstract}
In $2050,70 \%$ of the world population will live in cities, putting pressure on management to become intelligent and stakeholders gain relevance and interest as an object of study, starting to dispute the protagonism in these territories. We have't identified studies that recognize these stakeholders in smart cities. The objective was to identify them, as well as their attributes and their salience. We performed a systematic literature review and obtained 82 final documents. As a result, Civil society was the most cited stakeholder, followed by industries / companies, followed by governments and, finally, by academia / universities. The results, both by geographic region of study and by the academic background of the authors, refer to the same result. We did not identify any mention of the salience and attributes of stakeholders in smart cities, indicating a scientific gap to be studied in the future. Teaching and research was the least significant segment among the stakeholders, indicating the need to include this group as active protagonists in this process. We conclude that civil society needs to be effectively involved in these smart cities' initiatives, after all, these are the main shareholders of these cities.
\end{abstract}

Keywords: Stakeholders; Smart cities; Quadrupal helix; Systematic review.

\section{Resumen}

En 2050, el 70\% de la población mundial vivirá en ciudades, presionando a la gestión para que se vuelva inteligente y los actores ganen relevancia e interés como objeto de estudio, comenzando a disputar el protagonismo en estos territorios. No hemos identificado estudios que reconozcan a estas partes interesadas en las ciudades inteligentes. El objetivo era identificarlos, así como sus atributos y su relevancia. Realizamos una revisión sistemática de la literatura y obtuvimos 82 documentos finales. Como resultado, la sociedad civil fue el actor más citado, seguida de las industrias / empresas, seguida de los gobiernos y, finalmente, de la academia / universidades. Los resultados, tanto por región geográfica de estudio como por formación académica de los autores, hacen referencia al mismo resultado. No identificamos ninguna mención de la relevancia y los atributos de las partes interesadas en las ciudades inteligentes, lo que indica una brecha científica que se estudiará en el futuro. La docencia y la investigación fue el segmento menos significativo entre los actores, lo que indica la necesidad de incluir a este grupo como protagonistas activos en este proceso. Concluimos que la sociedad civil debe involucrarse de manera efectiva en estas iniciativas de ciudades inteligentes, después de todo, estos son los principales accionistas de estas ciudades.

Palabras clave: Partes intresadas; Ciudades inteligentes; Hélice cuádruple; Revisión sistemática. 


\section{Introdução}

As cidades estão no centro dos desafios e soluções do mundo. Ao ocupar apenas 3\% das terras da Terra, são os motores de crescimento econômico com $80 \%$ do PIB global (ONU-Habitat, 2015), também é o local onde a maioria das inovações são criadas e, ao mesmo tempo em que, 75\% dos gases de efeito estufa globais são produzidos (ONU, 2016). Em um nível global, a Navigant Research (2011) estimou que cerca de \$ 100 bilhões nos próximos dez anos seriam investidos em tecnologias para apoiar cidades inteligentes (Kummitha \& Crutzen, 2017). Neste contexto, as partes interessadas, ou stakeholders, ganham relevância e interesse enquanto objeto de estudo, ultrapassando as barreiras do estrito ambiente corporativo para disputar o protagonismo no âmbito destas smart cities (UKTI, 2015).

Não há consenso em relação a um conceito unificado para o termo. A literatura remete a uma cidade inteligente como aquela em que os investimentos em capital humano e social e tradicional (transporte) e a infraestrutura de comunicação moderna (TIC) alimenta o crescimento econômico sustentável e uma alta qualidade de vida, com uma gestão criteriosa dos recursos naturais, por meio da participação governamental (Caragliu, Del Bo, Chiara, Nijkamp \& Peter, 2009). Já as partes interessadas referem-se aos "grupos sem cujo apoio a organização deixaria de existir" ou ainda como qualquer grupo ou indivíduo que pode afetar ou é afetado pela realização dos objetivos da organização (Freeman, 1984).

Da análise da literatura então disponível, identificamos extensa literatura em relação às partes interessadas, no entanto, com enfoque em organizações privadas. Passadas mais de três décadas desde a obra de Freeman Strategic Management (1984) considerado o tratado dos Stakeholders, não há estudo relevante e suficiente que busque identificar estas partes interessadas no contexto das cidades inteligentes, tampouco aferir sua importância neste processo. Neste sentido, nosso objetivo foi identificar como a literatura reconhece os stakeholders nas smart cities, quem são, seus atributos e saliência, sob as lentes da formação acadêmica dos respectivos autores e de acordo com a região objeto de estudo dos artigos.

Para tanto utilizamos o método da revisão sistemática da literatura como um processo de investigação primária necessária para contextualizar as partes interessadas e as cidades inteligentes. A base Scopus foi utilizada em busca dos artigos científicos em língua inglesa disponíveis para os anos 2000 a 2019 e que continham nos seus títulos, palavras-chave e resumos as palavras stakeholder(s) e smart city(ies). A base inicial contendo 727 artigos foi reduzida a 82 documentos finais, após executados os filtros e critérios de classificação adotados.

Os resultados deram pela sociedade civil como o stakeholder (ou conjunto deles) mais citado, seguido pelas indústrias e companhias, na sequência pelos governos e, por último, pela academia e universidades. Os resultados por região geográfica de estudo e ainda de acordo com a formação acadêmica dos autores, remetem ao mesmo resultado.

Não há na literatura menção à saliência e aos atributos dos stakeholders das smart cities, indicando lacuna científica a ser estudada em trabalhos futuros.

O segmento de ensino e pesquisa - universidades, escolas técnicas, centros de pesquisa etc. - revelam-se os menos significativos entre os stakeholders citados, o que indica a necessidade de inserção deste grupo como partes interessadas ativas no processo de concepção e implantação cidades inteligentes.

Outra contribuição deste artigo vem no sentindo de que a sociedade civil, embora muito citada, carece de ouvir e ser ouvida efetivamente nestas smart cities, afinal de contas, seriam estes os principais acionistas destas cidades.

\section{Fundamentos Teóricos}

Esta seção é composta pela origem do termo stakeholder, sua perspectiva organizacional, e sua perspectiva pelas cidades inteligentes. 


\subsection{Origem do termo stakeholder}

A origem do termo Stakeholders é trazida por R. Edward Freeman que, em 1984 publica o livro Strategic Management: A Model for Strategic Management. Segundo ele, a primeira utilização do termo Stakeholders deu-se em 1963 em uma conferência realizada em Stanford Research Institute (SRI) para se referir àqueles "grupos sem cujo apoio a organização deixaria de existir". O termo pretendia ampliar a noção de acionista como o único grupo a quem a administração precisaria responder, passando a incluir funcionários, clientes, fornecedores, credores e sociedade, ou seja, "um indivíduo ou grupo de indivíduos que pode afetar ou ser afetado pela conquista dos objetivos organizacionais".

\subsection{Stakeholders pela perspectiva organizacional}

Freeman (1984) identificou como partes interessadas à organização, os empregados, grupos de interesse especial, ambientalistas, fornecedores, governos, organizações comunitárias locais, proprietários, advogados do consumidor, clientes, concorrentes e meios de comunicação. Uma maneira de entender a definição é pensar no conceito das partes interessadas como um guarda-chuva para os problemas nos negócios, estratégia e capacidade de resposta social corporativa (Freeman, 1984).

Para ilustrar as diversas definições, a Tabela 1, adaptada de Boucher (2016), traz as definições em ordem cronológica da data da publicação das fontes.

Tabela 1. O que é uma parte interessada? Cronologia.

\begin{tabular}{|c|c|}
\hline Fonte & Definição \\
\hline $\begin{array}{l}\text { Memorando de Stanford } \\
\qquad(1963)\end{array}$ & $\begin{array}{l}\text { “Aqueles grupos sem cujo apoio a organização deixaria de } \\
\text { existe" (citado em Freeman e Reed 1983; Freeman 1984) }\end{array}$ \\
\hline Rhenman (1964) & $\begin{array}{l}\text { "Dependem da empresa para atingir seus objetivos pessoais e } \\
\text { de quem a empresa depende para sua existência" }\end{array}$ \\
\hline $\begin{array}{l}\text { Ahlstedt e } \\
\text { Jahnukainen (1971) }\end{array}$ & $\begin{array}{c}\text { "Motivados por seus próprios interesses e objetivos são participantes de uma empresa e, } \\
\text { portanto, dependendo dele e de quem, por sua causa, a empresa depende" (citado em } \\
\text { Näsi 1995) }\end{array}$ \\
\hline Freeman e Reed & $\begin{array}{c}\text { Amplo: "pode afetar a consecução dos objetivos de uma organização ou quem é afetado } \\
\text { pela consecução dos objetivos de uma organização" }\end{array}$ \\
\hline (1983: 91) & $\begin{array}{l}\text { Estreito: “do qual a organização depende para sua continuidade } \\
\text { sobrevivência" }\end{array}$ \\
\hline
\end{tabular}

Freeman (1984: 46)

"Pode afetar ou é afetado pela conquista dos objetivos da organização"

Freeman e Gilbert

(1987: 397)

"Pode afetar ou é afetado por uma empresa"

Cornell e Shapiro

(1987: 5)

"Requerentes" que têm "contatos"

Evan e Freeman

(1988: 75-76)

"Participar ou reivindicar na empresa" 
Evan e Freeman

(1988: 79)
"Beneficiam ou são prejudicados e cujos direitos são violados ou respeitados por ações corporativas "

Bowie (1988a, b:

112 , nota 2 )

"Sem cujo apoio a organização deixaria de existir"

Alkhafaji (1989: 36)

"grupos pelos quais a corporação é responsável"

"Afirma ter um ou mais desses tipos de apostas" - "variando de

Carroll (1989: 57) interesse em um direito (legal ou moral) de propriedade ou titularidade legal dos ativos ou propriedades da empresa"

Evan e Freeman

(1990)

"Titulares de contrato".

Thomson et al.

(1991: 209)

No "relacionamento com uma organização"

Savage et al.

(1991: 61)

"Tenha interesse nas ações de uma organização e... a capacidade de influenciá-lo"

Hill and Jones

"Constituintes que têm uma reivindicação legítima da firma... estabelecida através da

(1992: 133) existência de um relacionamento de troca "que forneça" a empresa com recursos críticos (contribuições) e em troca espera que seus interesses sejam satisfeitos (por incentivos) "

\begin{tabular}{cc}
\hline Brenner (1993: 205) & $\begin{array}{c}\text { "tendo algum relacionamento legítimo e não trivial com uma organização (como) } \\
\text { transações de câmbio, impactos de ações e ações morais responsabilidades" }\end{array}$ \\
\hline Carroll (1993: 60) & "Afirma ter um ou mais desses tipos de participação nos negócios" - pode ser afetado ou \\
afetar...
\end{tabular}

Freeman (1994: 415)

"Participantes do "processo humano de criação de valor"

Wicks et al. (1994:

483)

"Interagir e dar significado e definição à corporação"

Langtry (1994: 433)

"A empresa é significativamente responsável pelo seu bem-estar ou detém uma moral ou legal sobre a empresa"

Starik (1994: 90)

"Podem ou estão divulgando suas apostas" - "são ou podem ser influenciados por, ou são ou são potencialmente influenciadores ou alguma organização"

Clarkson (1995: 5)

"Suportam alguma forma de risco como resultado de terem investido alguma forma de capital, humano ou financeiro, algo de valor em uma empresa "ou" são colocados em risco como resultado das atividades de uma empresa"

Clarkson (1995: 106)

"Possui, ou reivindica, propriedade, direitos ou interesses em uma corporação e suas atividades" 
Brenner (1995: 76,

Nota 1)

Donaldson e

Preston (1995: 85)
"Fazer ou que poderia impactar ou ser impactado pela empresa / organização"

"Pessoas ou grupos com interesses legítimos em procedimentos e / ou aspectos substantivos da atividade corporativa"

Fonte: Adaptado de Stakeholder theory: A model for strategic management de Boucher e Maria B., Rendtorff, Jacob D., 2016, Paris:

Springer International Publishing AG Switzerland, p. 3-4.

Observa-se da Tabela 1 que os estudos, então transcorridas mais de três décadas desde o Memorando de Stanford (1963), ainda focavam o ambiente corporativo e as partes interessadas a ele relacionadas.

Originalmente, Freeman (1984) apresentou os seguintes stakeholders (internos e externos) e o seu nível de relacionamento com a organização, conforme Figura 1.

Figura 1. Stakeholders sob a Perspectiva da Organização.

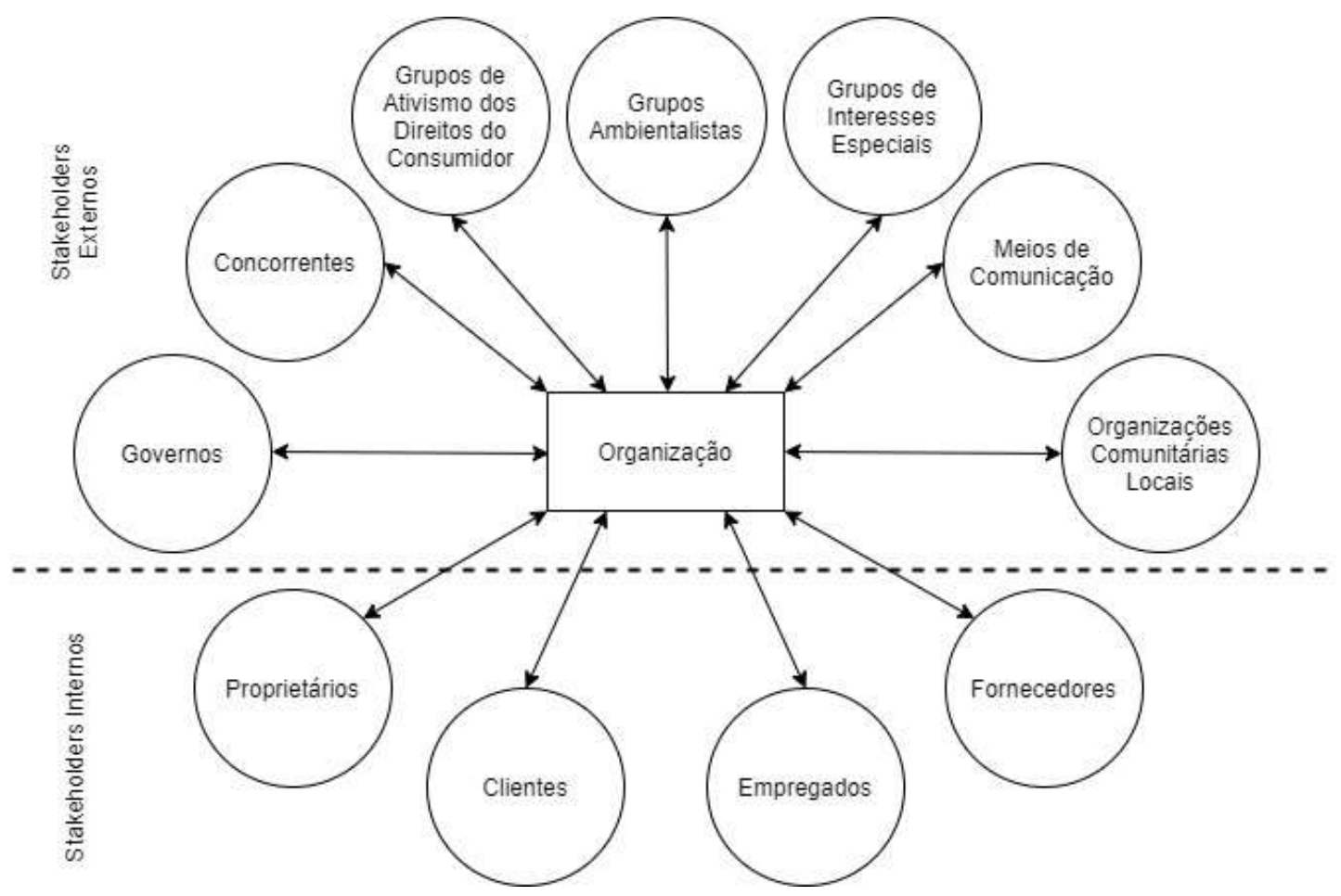

Fonte: Adaptado de Freeman, Robert E. (1984). Strategic management. Melbourne: Pitman Publishing Pty. Ltd.

Adaptamos a Figura 1 a partir da originalmente apresentada por Freeman (1984) de modo a demonstrar, de forma segregada, os stakeholders internos e externos à corporação, para os quais passamos a discorrer a seguir.

Proprietários internos:

a) Proprietários: não basta aos CEOs atenderem tão somente aos interesses dos proprietários e acionistas. O desafio é equacionar demandas por resultados e investimentos para cenários de curto e longo prazo;

b) Clientes: o domínio das organizações locais e nacionais na oferta de produtos e serviços acabou migrando para uma variedade a partir de um mercado globalizado e com novos padrões de qualidade, mudando drasticamente, por consequência, as relações com os clientes;

c) Empregados: recomendável repensar o relacionamento gerente-funcionário. Estilos de gestão mais autoritários 
devem ser substituídos por uma abordagem mais humana e participativa, atentando-se à cultura e aos valores presentes nos funcionários, o que resultaria em maior produtividade e, por consequência, melhores resultados à organização;

d) Fornecedores: outros aspectos ganham relevância no relacionamento da organização com seus fornecedores tais como as questões políticas e políticas de controle fazendo-se tão importantes quanto em relação à questão de preço e qualidade dos suprimentos.

Proprietários externos:

a) Governos: o gerenciamento das organizações é influenciado pela estrutura legal, regulatória e institucional agências, comitês, comissões, ministérios e secretarias - e ainda pelos vários níveis de governo e pelas políticas públicas adotadas. A burocracia estatal prevalece neste contexto, revelando-se como um custo a ser assimilado no processo produtivo. Cabe à gestão organizacional empreender o esforço necessário para lidar com os governos de forma estratégica;

b) Concorrentes: no mercado globalizado a concorrência ganha relevância na medida em que produtos estrangeiros ganham competitividade, às vezes de modo repentino, a partir de contextos e conjunturas internacionais, resultando, portanto, na ruptura da prevalência constante dos bens e serviços produzidos em âmbito local;

c) Grupos de Ativismo dos Direitos do Consumidor: o ativismo na defesa do consumidor muitas das vezes é midiático e popular. Uma vez insatisfeito com um determinado produto, pode o consumidor simplesmente deixar de comprar ou exercer seu direito de voz, pressionando o governo ou a organização, podendo evoluir a uma demanda judicial;

d) Grupos Ambientalistas: a preocupação com a qualidade ambiental impacta as decisões das organizações, seja pelos custos potencialmente envolvidos ou pelos resultados positivos ou negativos associados à imagem do produto ou da empresa, inclusive influenciando na sua competitividade;

e) Grupos de Interesses Especiais: trata-se daqueles grupos defensores de questões específicas, como controle de armas, aborto, oração nas escolas, dentre outros. A imprevisibilidade quanto ao momento de sua constituição ou tema é um desafio aos gestores organizacionais. Estes movimentos podem atrair mídia e influenciar no aspecto legal e regulatório, afetando, por óbvio, o ambiente de negócios e a estratégia das organizações;

f) Meios de Comunicação: a mídia é capaz de influenciar o ambiente interno e externo à organização, sobretudo quando se trata de comunicação de massa, fazendo-se mais um desafio à gestão organizacional;

g) Organizações Comunitárias Locais: são organizações formais e informais que defendem os interesses de comunidades locais, como, por exemplo, amigos de bairro, associação de moradores etc.

Numa tentativa de classificar as partes interessadas, Mitchell, Agle e Wood. (1997) propuseram o critério baseado em três perguntas: Qual é o poder real ou potencial que as partes interessadas têm na sociedade, permitindo-lhes impor sua vontade a uma corporação? Que tipo de legitimidade eles possuem? E com que urgência uma organização precisa responder a suas demandas? Poder, legitimidade e urgência são os atributos destas partes interessadas e podem ser utilizados para identificar diferentes classes de interessados em um ambiente empresarial. Mitchell et al. (1997) apresentaram ainda o conceito de saliência das partes interessadas, sugerindo um modelo dinâmico, baseado na tipologia de identificação, que permite o reconhecimento explícito da singularidade situacional e gerencial para explicar como os gerentes priorizam relacionamentos com as partes interessadas. A identificação de quais partes interessadas realmente existem, quais a tipologia de identificação proposta facilita e porque os gerentes respondem a eles à maneira como eles fazem, visando especificar como e em que stakeholders os gerentes de podem e devem responder.

\subsection{Stakeholders pela perspectiva das smart cities}

Muito embora sua origem remeta à década de 1990 (Fernandez-Anez, Fernández-Güell \& Giffinger, 2018; Hosseini, Frank, Fridgen \& Heger, 2018; Li, Liu, Dai \& Zhao, 2019; Milošević, M.R., Milošević, D. M., Stević \& Stanojević, 2019; 
Myeong, Jung \& Lee, 2018; Praharaj \& Han, 2019), o termo cidades inteligentes ainda não possui uma definição absoluta (Marek, Campbell \& Bui, 2017) ou universalmente aceita (Praharaj \& Han, 2019), é ambíguo, carecendo de clareza e nitidez (Freudendal-Pedersen, Kesselring \& Servou, 2019), portanto difuso e utilizado de maneira nem sempre consistente (Marrone \& Hammerle, 2018). Com o objetivo de ilustrar o entendimento acerca da definição de cidades inteligentes, apresentamos na Tabela 2 os conceitos comuns na literatura.

Tabela 2. Definições comuns de cidades inteligentes.

\begin{tabular}{|c|c|}
\hline Autor & Definição \\
\hline $\begin{array}{l}\text { Bowerman et al. } \\
\qquad(2000)\end{array}$ & $\begin{array}{l}\text { Uma cidade que monitora e integra as condições de todas as suas infraestruturas críticas, } \\
\text { incluindo estradas, pontes, túneis, trilhos, metrôs, aeroportos, portos marítimos, } \\
\text { comunicações, água, energia, mesmo grandes edifícios, podem otimizar melhor seus } \\
\text { recursos, planejar suas atividades de manutenção preventiva e monitorar os aspectos de } \\
\text { segurança, maximizando os serviços aos seus cidadãos. }\end{array}$ \\
\hline $\begin{array}{l}\text { Giffinger et al. } \\
\text { (2007) }\end{array}$ & $\begin{array}{c}\text { Uma cidade com bom desempenho de maneira voltada para o futuro em [economia, } \\
\text { pessoas, governança, mobilidade, meio ambiente e vida] baseada na combinação } \\
\text { inteligente de dotações e atividades de cidadãos autodeterminados, independentes e } \\
\text { conscientes. }\end{array}$ \\
\hline Rios (2008) & $\begin{array}{l}\text { Uma cidade que inspira, compartilha cultura, conhecimento e vida, uma cidade que } \\
\text { motiva seus habitantes para criar e florescer em suas próprias vidas. Uma cidade } \\
\text { admirada, um navio para inteligência, mas, em última análise, uma incubadora de } \\
\text { espaços com poderes. }\end{array}$ \\
\hline $\begin{array}{l}\text { Caragliu et al. } \\
\text { (2009) }\end{array}$ & $\begin{array}{l}\text { Uma cidade para ser inteligente ao investir em capital humano e social e tradicional } \\
\text { (transporte) e infraestrutura de comunicação moderna (TIC) combustível para o } \\
\text { crescimento econômico sustentável e alta qualidade de vida, com uma gestão criteriosa } \\
\text { dos recursos naturais, por meio de governança participativa. }\end{array}$ \\
\hline
\end{tabular}

Uma ideia particular de comunidade local, onde governos municipais, empresas e Eger (2009) residentes usam as TICs para reinventar e reforçar o papel da comunidade na nova economia de serviços, criar empregos localmente e melhorar a qualidade de vida da comunidade.

\begin{tabular}{|c|c|}
\hline $\begin{array}{l}\text { González e Rossi } \\
\text { (2011) }\end{array}$ & $\begin{array}{l}\text { Uma administração pública ou autoridades que entrega (ou visa) um conjunto de nova } \\
\text { geração de serviços e infraestruturas, com base em tecnologias de informação e } \\
\text { comunicação. }\end{array}$ \\
\hline $\begin{array}{l}\text { Nam e Pardo } \\
\quad(2011)\end{array}$ & $\begin{array}{l}\text { Uma cidade humana que tem múltiplas oportunidades de explorar seu potencial humano } \\
\text { e liderar uma vida criativa. }\end{array}$ \\
\hline Zhao (2011) & $\begin{array}{l}\text { Melhorar a qualidade de vida em uma cidade, incluindo aspectos ecológicos, culturais, } \\
\text { políticos, institucionais, componentes sociais e econômicos sem deixar um fardo para as } \\
\text { gerações futuras. }\end{array}$ \\
\hline Lazaroiu (2012) & $\begin{array}{c}\text { A cidade inteligente representa o desafio do futuro, um modelo de cidade onde a } \\
\text { tecnologia está à serviço da pessoa e da melhoria da sua qualidade de vida econômica e } \\
\text { social. }\end{array}$ \\
\hline $\begin{array}{l}\text { Schaffers et al. } \\
\text { (2012) }\end{array}$ & $\begin{array}{l}\text { A cidade inteligente é conhecida como cidade urbana segura, de meio ambiente } \\
\text { protegido e centro urbano eficiente do futuro com infraestruturas avançadas, como } \\
\text { sensores, eletrônicos e redes para estimular o crescimento econômico sustentável e uma }\end{array}$ \\
\hline
\end{tabular}


alta qualidade de vida.

Uma cidade inteligente é concebida como um ambiente urbano que, apoiado por TIC

Piro et al. (2014) difundidas sistemas, é capaz de oferecer serviços avançados e inovadores aos cidadãos, a fim de melhorar a qualidade geral de suas vidas.

Yigitcanlar Uma cidade inteligente pode ser uma forma ideal de construir as cidades sustentáveis do século 21, no caso de uma visão equilibrada e sustentável sobre aspectos econômicos, sociais, ambientais onde o desenvolvimento institucional é realizado.

Fonte: Adaptado de Smartness that matters towards a comprehensive and human-centred characterization of smart cities de Lara, A. P., Da Moreira Costa, E., Furlani, T. Z., e Yigitcanlar, T. (2016), Brisbane: Journal of Open Innovation: Technology, Market, and Complexity, p. 6.

As definições são bastante difusas entre si variando da perspectiva mais tecnológica às abordagens mais centradas no ser humano e na sustentabilidade.

$\mathrm{Na}$ literatura encontramos alguns esforços em listar quais seriam as partes interessadas das cidades inteligentes. Dameri e Benevolo (2016) mencionaram cidadãos, empresas, organizações sem fins lucrativos e sociedade civil. Para Chaturvedi e Kolbe (2019), as partes interessadas das cidades inteligentes são os proprietários, operadoras, empresas de serviços públicos, fornecedores de sensores, cidadãos e visitantes. Governo, o setor privado, ONGs, cidadãos (Simonofski, Vanderose, Clarinval \& Snoeck, 2018) e cidadãos, agências e indústria (Axelsson \& Granath, 2018) são outras menções aos stakeholders das cidades inteligentes na literatura.

Dentre as diversas tentativas de conceitualizar e categorizar os stakeholders de uma cidade inteligente, Leydesdorff e Deakin (2011), definiram o conceito de hélice tríplice de uma cidade inteligente. A hélice é composta por universidades, indústrias e governos democráticos e suas interações produzem os conhecimentos que apoiam a evolução da cidade.

Lombardi e Giordano, Farouh e Yousef (2012) utilizaram-se deste método para medir o desempenho das cidades inteligentes incluindo à hélice tripla a sociedade civil, estabelecendo, portanto, a hélice quádrupla. A Figura 2, ilustra este modelo participativo da hélice quádrupla. 
Figura 2. Hélice Quádrupla no Domínio Participatório.

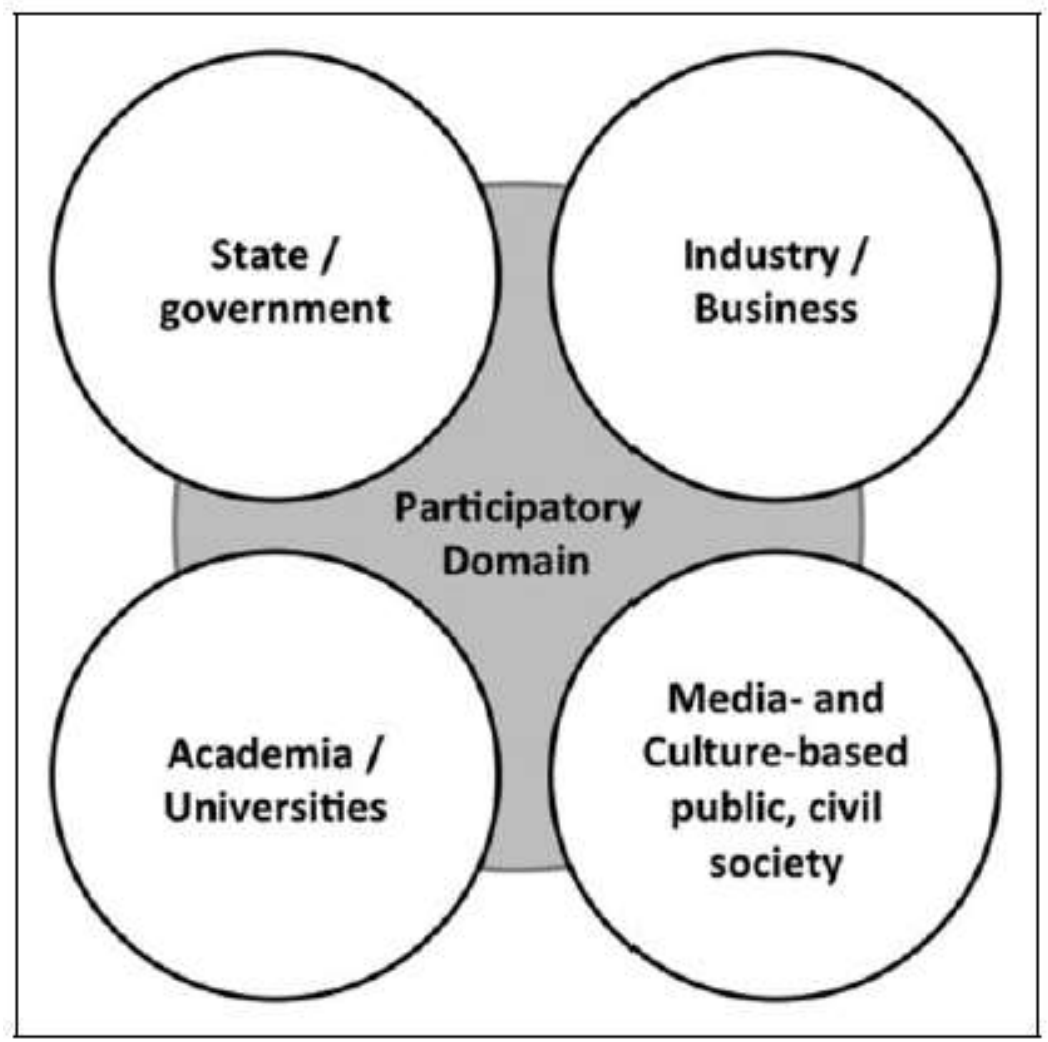

Fonte: van Waart, P., Mulder, I., e Bont, C. de (2016). A Participatory Approach for Envisioning a Smart City. Social Science Computer Review, 34(6), 708-723.

$\mathrm{Na}$ hélice quádrupla se faz possível classificar e agrupar todos os stakeholders de uma cidade a partir dos quatro segmentos nela contidos.

\section{Procedimentos Metodológicos}

Para realização desta pesquisa utilizamos o método qualitativo. Segundo Pereira, et al. (2018) a pesquisa qualitativa geralmente ocorre no ambiente natural com coleta direta de dados - preferencialmente descritivos - cuja análise tende a seguir um processo indutivo. A preocupação com o processo é predominante em relação ao produto, carecendo de interpretação e opinião por parte do pesquisador em relação ao fenômeno sob estudo.

Neste sentido, realizamos uma revisão sistemática de literatura (RSL) que consiste num processo de revisão de conteúdos

(pesquisas e estudos científicos) de natureza qualitativa que segue critérios rigorosos, baseados em evidências e tem como objetivo mapear, avaliar, identificar o território intelectual existente sobre um determinado tema de pesquisa (Tranfield, Denyer \& Smart, 2003). Este método oferece um rigor metodológico baseado em evidências e replicável, portanto, mais transparente e auditável por parte dos autores e pesquisadores (Quirino e Storopoli, no prelo).

Conforme os critérios estabelecidos para realização da RSL, este estudo foi dividido em etapas, sendo elas: 1 . Planejamento; 2. Condução da Revisão; e 3. Análise de dados. 


\subsection{Etapa 1 - Planejamento}

O planejamento iniciou-se a partir da definição do problema e da questão central de pesquisa, posteriormente sendo subdividido neste e nos dois capítulos seguintes, passando à revisão da literatura para identificação dos stakeholders relacionados às smart cities utilizando da base científica Scopus.

\subsection{Etapa 2 - Condução da revisão}

$\mathrm{Na}$ sequência passamos à coleta de dados. Nesta fase foi descrito com detalhes o protocolo com os parâmetros utilizados para gerar a base de dados e informações inicial que serviu para execução da RSL.

Neste momento é fundamental detalhar todo o processo de coleta de forma que outras pessoas possam replicá-lo.

Para identificar os Stakeholders em smart cities realizamos, em julho de 2020, busca bibliométrica na base de dados Scopus contendo a seguinte sentença: TITLE-ABS-KEY("stakeholder\$" AND "smart cit*") AND PUBYEAR > 1999 AND PUBYEAR < 2020. Tal sentença retornou com todos os documentos publicados entre os anos 2000 e 2019 contendo os termos stakeholder(s) e smart city(ies) no título, resumo ou palavras-chave. Foram 727 documentos identificados considerando estes critérios. Restringindo a busca a artigos em língua inglesa e, eliminando duplicidades, chegamos a 239 documentos. A escolha do período de publicação a partir de 1999, deu-se por conta da inexistência de literatura em quantidade relevante no período anterior a este. A tabela contendo os 239 documentos da amostra pode ser consultada no link https://osf.io/xcgw4/?view_only=bd07932b8a3a4d728c8544e1fb7a7c8e.

Com o objetivo de identificar quais são os stakeholders nas smart cities, seus atributos e saliência, realizamos busca textual nos resumos de todos os artigos de modo a identificar as expressões 'smart city' ou 'smart cities' e 'stakeholder' ou 'stakeholders' de modo simultâneo. Os documentos nos quais se identificavam os termos foram tagueados como 'selecionados', enquanto que, aqueles em que não se identificavam foram desconsiderados da base. Dos 239 arquivos, restaram 196 selecionados e 6 artigos para avaliação quanto à pertinência ou não da exclusão da base de dados.

Da leitura de todos os títulos e resumos destes artigos selecionados e em avaliação identificando aqueles que guardam inequívoca relação (que tenham como enfoque principal) restaram 125 artigos. Nestes, realizamos pesquisa textual no arquivo PDF em busca dos seguintes termos e suas derivações plurais: atribute, power, legitimacy, urgency e salience. Foram desconsiderados os resultados que não se localizavam no corpo do artigo. Após a aplicação deste critério de escolha restaram 91 artigos, sendo 25 eliminados por não terem sido localizados os termos pesquisados. Outros 9 documentos foram descartados por razões de ordem técnica - não se tratavam de artigos científicos ou eram artigos incompletos.

$\mathrm{Na}$ sequência realizamos a leitura dinâmica dos 25 artigos eliminados nos quais não foram localizados os termos pesquisados numa tentativa de identificar relação direta - enfoque principal com o tema da pesquisa (stakeholders em smart cities). O objetivo seria o de reconsiderar artigos que, muito embora não apresentassem expressamente os termos relacionados aos atributos e a saliência eventualmente relacionados aos stakeholders, pudessem novamente serem incluídos na base de dados por guardarem relação com o objeto deste estudo, portanto, enriquecendo-a. Foram reconsiderados 9 artigos. Portanto, a amostra final é de 100 artigos.

Por último, passamos à leitura integral com objetivo de identificar quais os stakeholders mencionados nestes textos, bem como se haveria menção aos atributos e à saliência destes no contexto das cidades inteligentes. Identificamos também a área de formação acadêmica de cada um dos autores, utilizando-se, para tanto, a tabela de áreas de conhecimento disponibilizada pela CAPES - Coordenação de Aperfeiçoamento de Pessoal de Nível Superior e pelo CNPQ - Conselho Nacional de Desenvolvimento Científico e Tecnológico, ambos os órgãos vinculados ao Governo Federal Brasileiro, conforme disponibilizado no link https://osf.io/xcgw4/?view_only=bd07932b8a3a4d728c8544e1fb7a7c8e.

Também identificamos o local de estudo a que se referiam os textos, de modo a gerar uma visão segmentada das 
partes interessadas de acordo com a região geográfica. O local foi atribuído quando expressamente evidenciado no corpo do artigo. Para aqueles textos em que não se pôde obter a precisa adequada identificação do local de estudo ou para os casos de estudos teóricos, atribuímos a classificação como local indefinido.

Figura 3. Fluxograma da Condução da Revisão.

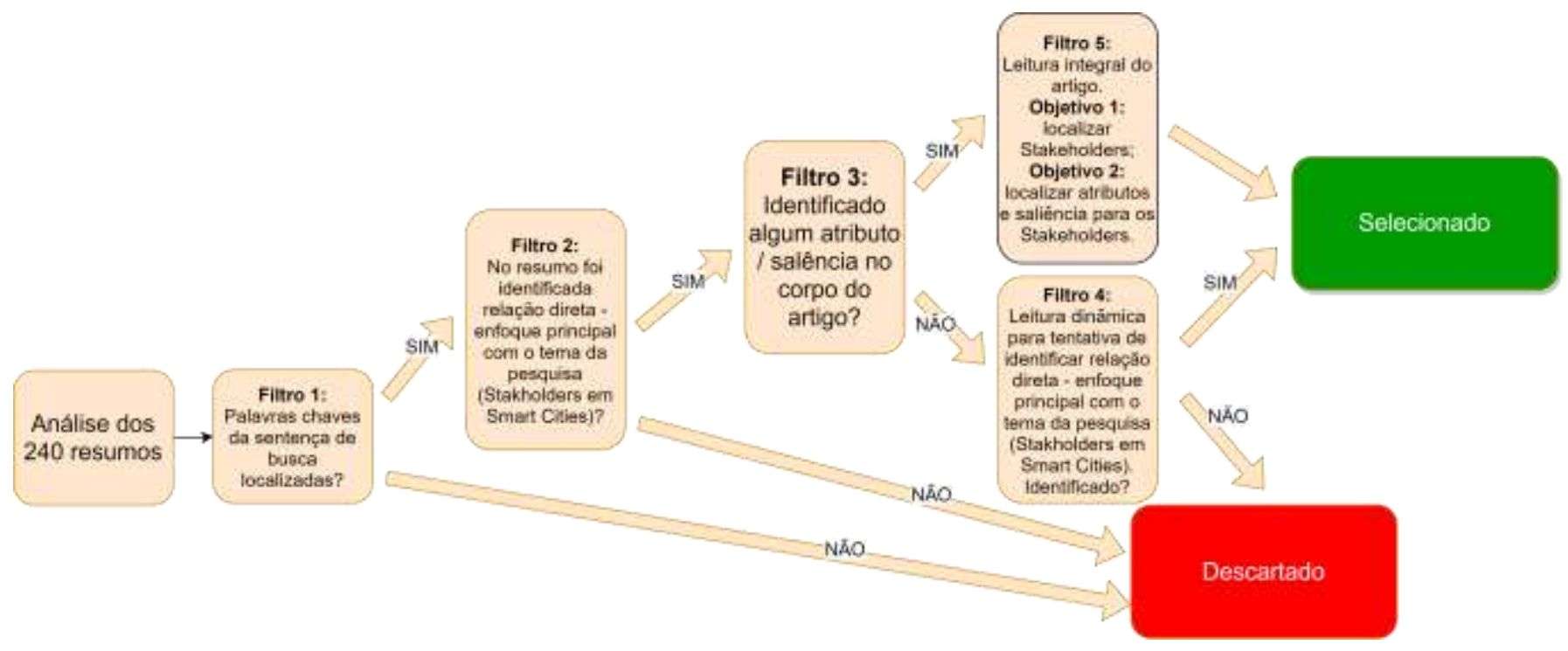

Fonte: Autores.

A Figura 3 evidencia o processo indutivo, rigoroso e transparente utilizado no levantamento dos dados utilizados nesta pesquisa.

Conclusos os procedimentos de análise, os resultados foram tabelados, contabilizadas as ocorrências para cada stakeholder identificado e agrupados de acordo com os seguintes critérios: região geográfica dos locais estudados, formação acadêmica dos autores e ainda de acordo com o conceito da hélice quádrupla de Lombardi et al. (2012), apresentado na sessão 2.3 deste trabalho.

A Figura 3 ilustra o fluxograma da condução da revisão e critérios de seleção dos artigos.

\subsection{Análise de dados}

Dos 100 artigos verificados em absolutamente nenhum se identificou qualquer um dos atributos ou saliência relacionados aos stakeholders.

$\mathrm{Na}$ Tabela 3 apresentamos os 10 principais stakeholders identificados na literatura conforme a quantidade de ocorrências. 
Research, Society and Development, v. 10, n. 1, e44410111931, 2021

(CC BY 4.0) | ISSN 2525-3409 | DOI: http://dx.doi.org/10.33448/rsd-v10i1.11931

Tabela 3. Stakeholders e quantidade de ocorrências.

\begin{tabular}{|c|c|c|}
\hline Position & Stakeholder & Occurrences \\
\hline 1 & Residente/Cidadão (Resident/Citizen) & 63 \\
\hline 2 & $\begin{array}{l}\text { Governo e Autoridades / Formuladores de Políticas } \\
\text { (Government and Authorities/Policy Makers) }\end{array}$ & 62 \\
\hline 3 & Empresas/Indústrias (Companies/Industry) & 52 \\
\hline 4 & $\begin{array}{l}\text { Academia/Universidades/Escolas técnicas } \\
\text { (Academy/Universities/Technical Schools) }\end{array}$ & 30 \\
\hline 5 & Empresas de TIC (ICT Companies) & 29 \\
\hline 6 & $\begin{array}{l}\text { Pesquisadores/Centros de Pesquisa (Researchers/Research } \\
\text { Centres) }\end{array}$ & 21 \\
\hline 7 & ONG $(N G O)$ & 17 \\
\hline 8 & Profissionais de TIC (ICT Professionals) & 16 \\
\hline 9 & Empresas de Serviços Públicos (Utility Companies) & 15 \\
\hline 10 & Organização da Sociedade Civil (Civil society organization) & 13 \\
\hline
\end{tabular}

Fonte: Autores.

Em 82 artigos identificamos, de modo expresso às cidades inteligentes, os respectivos stakeholders. Identificamos 65 diferentes partes interessadas, sendo as mais mencionadas, os cidadãos e residentes (63), governo e governantes (62) e indústrias e companhias (52). Os resultados na sua integralidade estão disponibilizados no link https://osf.io/xcgw4/?view_only=bd07932b8a3a4d728c8544e1fb7a7c8e.

Na sequência agrupamos os resultados da Tabela 3 de acordo com a hélice quádrupla - conforme seção 2.3. 
Research, Society and Development, v. 10, n. 1, e44410111931, 2021

(CC BY 4.0) | ISSN 2525-3409 | DOI: http://dx.doi.org/10.33448/rsd-v10i1.11931

Figura 4. Stakeholders Agrupados em Hélice Quádrupla.

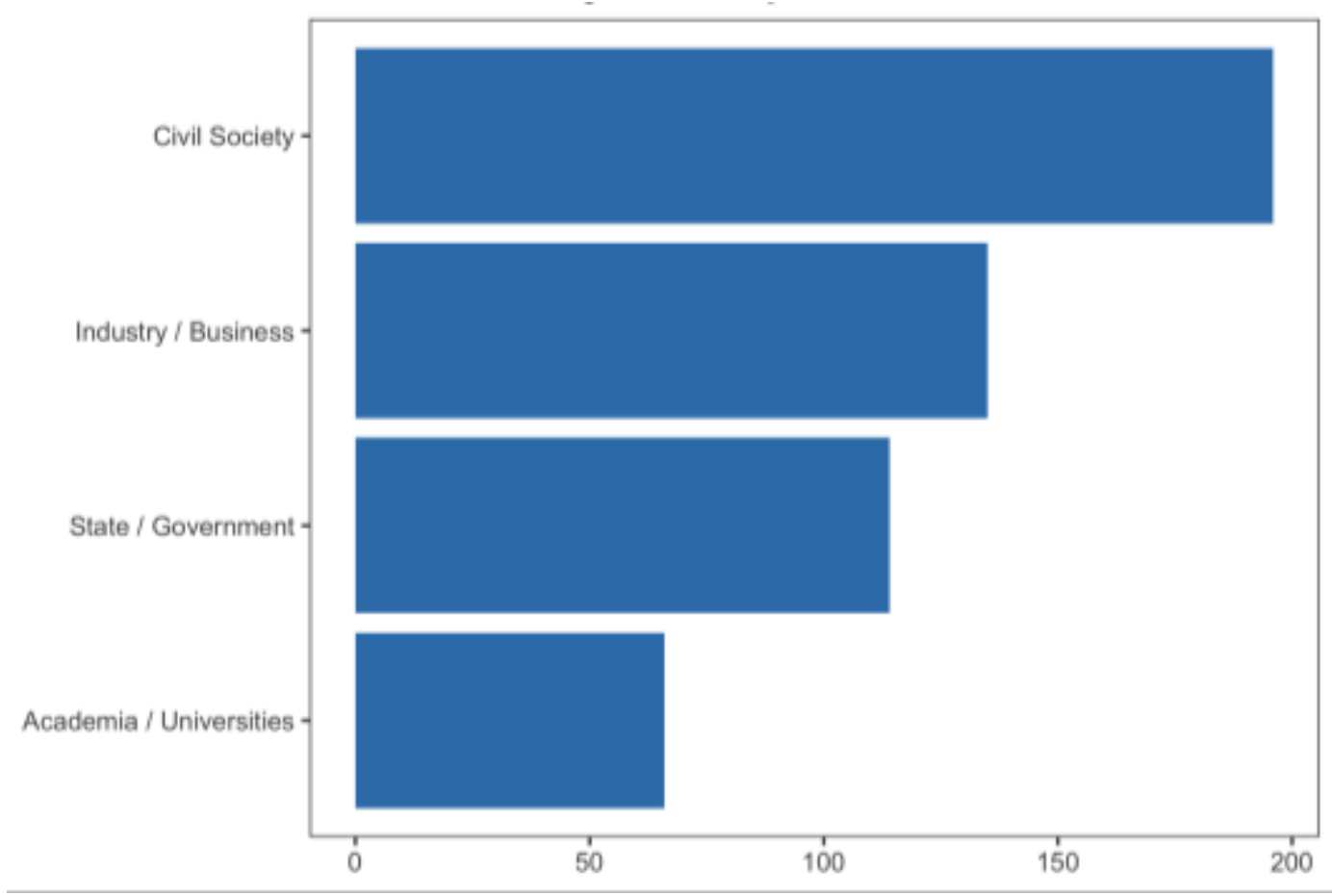

Fonte: Autores.

Observamos a sociedade civil como a mais representada (196), seguida pela indústria e negócios (135) e por estados e governos (114).

Agrupamos os artigos de acordo com a região geográfica dos estudos e apresentamos na Figura 5.

Figura 5. Artigos por Região Geográfica.

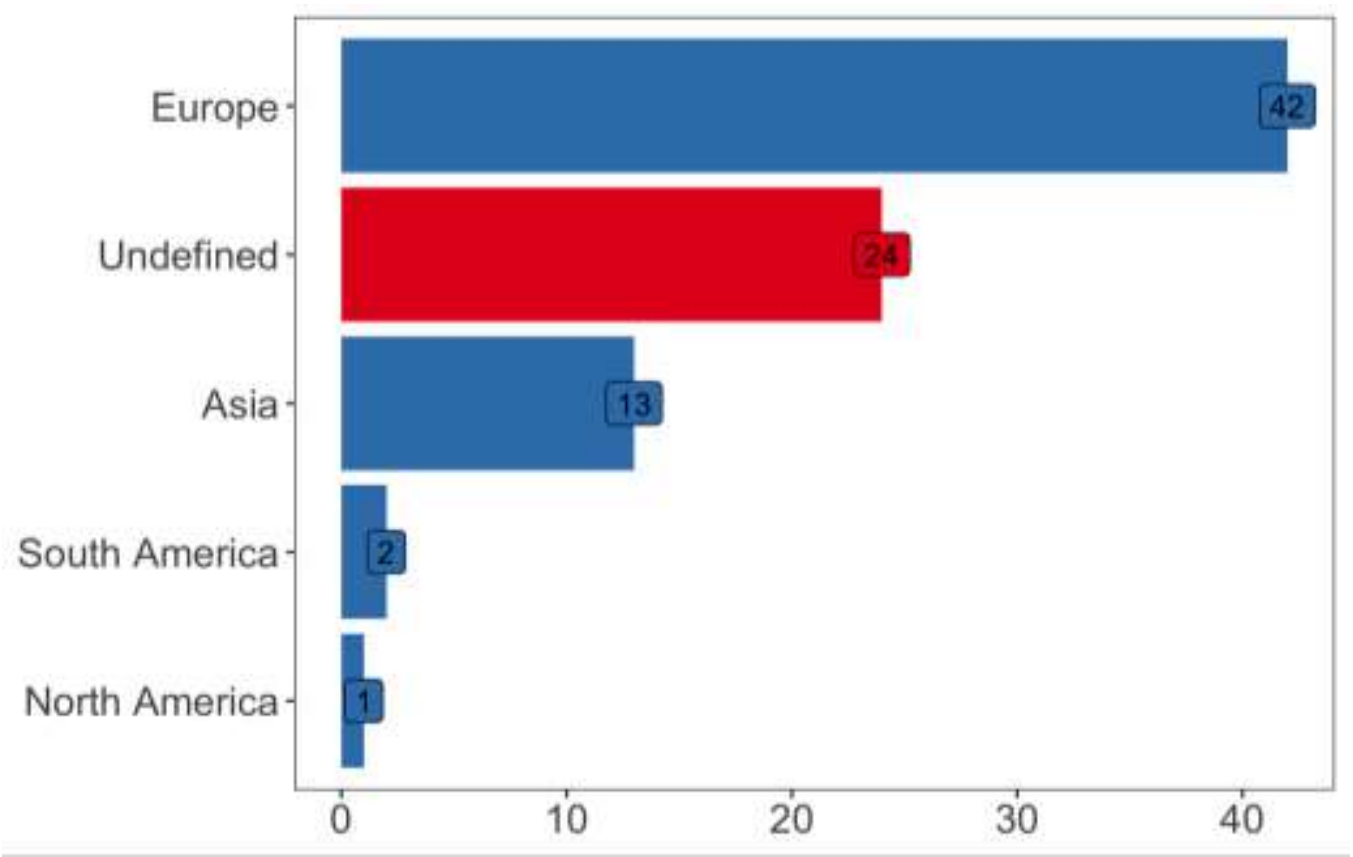

Fonte: Autores. 
$\mathrm{Na}$ abordagem conforme a região geográfica, temos que, a maioria dos artigos remetem à Europa (42). O continente asiático foi objeto de 13 estudos. 24 textos não remeteram a algum local específico ou não ofereceram evidências quanto a estes.

Além do agrupamento geográfico, também os classificamos de acordo com a hélice quádrupla, obtendo os resultados conforme Figura 6.

Figura 6. Stakeholders em Hélice Quádrupla Conforme a Região Geográfica.
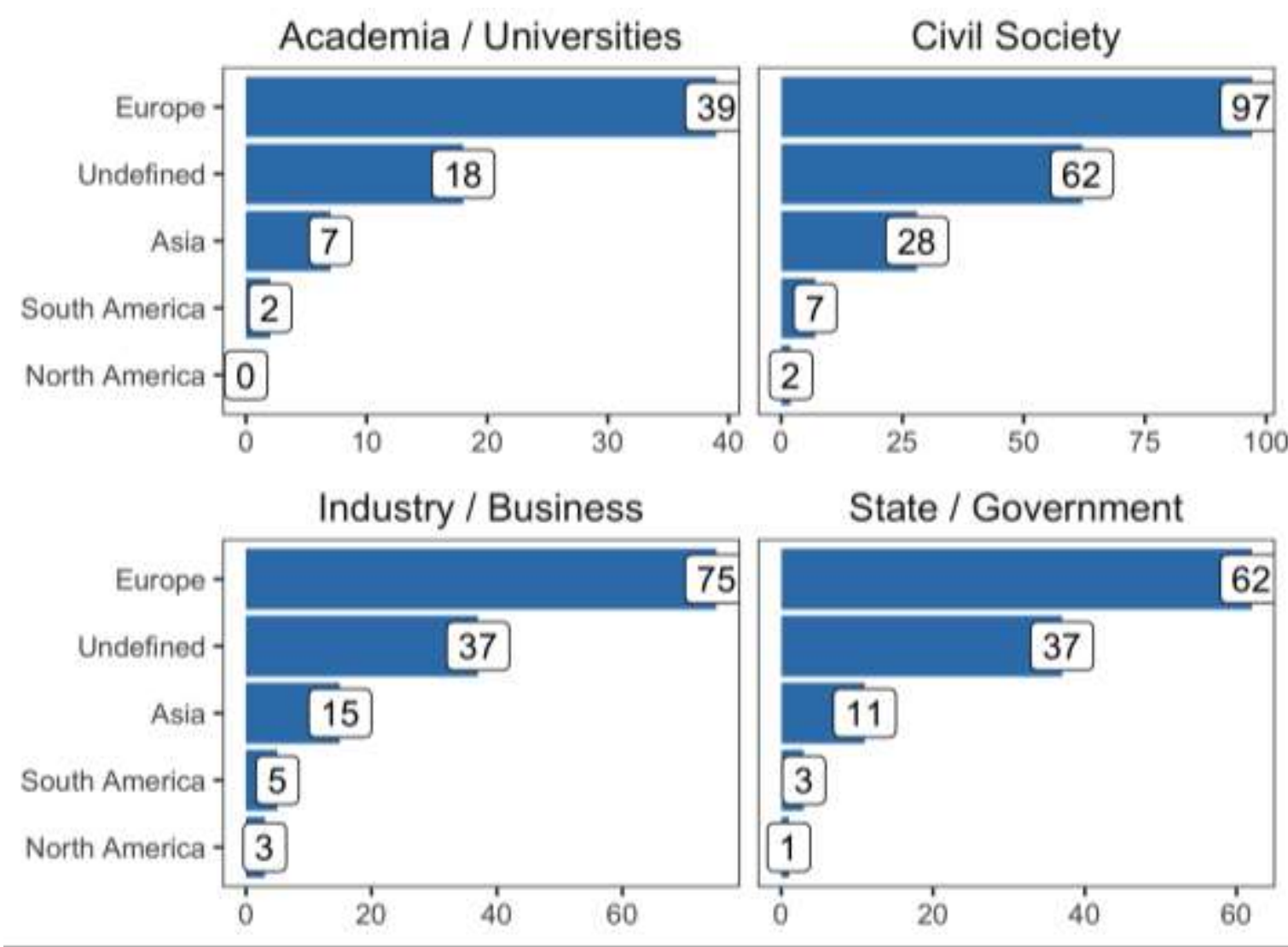

Fonte: Autores.

Conforme se observa, a sociedade civil é o segmento mais representado, seguido por indústria e negócios, por estados e governos e, por último, pela academia e universidades.

$\mathrm{Na}$ Tabela 4 apresentamos os quantitativos de autores por área do conhecimento. Já na Figura 7 evidenciamos quais os principais stakeholders a partir da respectiva formação acadêmica destes autores. 
Research, Society and Development, v. 10, n. 1, e44410111931, 2021

(CC BY 4.0) | ISSN 2525-3409 | DOI: http://dx.doi.org/10.33448/rsd-v10i1.11931

Tabela 4. Autores por área do conhecimento.

\begin{tabular}{lc}
\hline \multicolumn{1}{c}{ Area of knowlegde } & Occurrences \\
\hline Ciência da Computação (Computer Science) & 68 \\
\hline Economia (Economy) & 60 \\
\hline Engenharia (Engineering) & 45 \\
\hline Administração (Administration) & 26 \\
\hline Indefinida (Undefined) & 13 \\
\hline Humanas (Humanities) & 11 \\
\hline Comunicação (Communication) & 9 \\
\hline Urban and Regional Planning & 9 \\
\hline Architecture and urbanism & 8 \\
\hline Geosciences & 2 \\
\hline Sustainability & 1 \\
\hline Arts & Continua \\
\hline Law & Conclusão \\
\hline
\end{tabular}

Fonte: Autores.

De acordo com a formação acadêmica dos autores, temos que ciência da computação (68), economia (60) e engenharia (45) foram as áreas do conhecimento que mais trataram dos stakeholders das smart cities.

Agrupamos os stakeholders de acordo com a formação dos autores e a partir da hélice quádrupla conforme Figura 7. 
Research, Society and Development, v. 10, n. 1, e44410111931, 2021

(CC BY 4.0) | ISSN 2525-3409 | DOI: http://dx.doi.org/10.33448/rsd-v10i1.11931

Figura 7. Stakeholders Conforme a Formação dos Autores em Hélice Quádrupla.

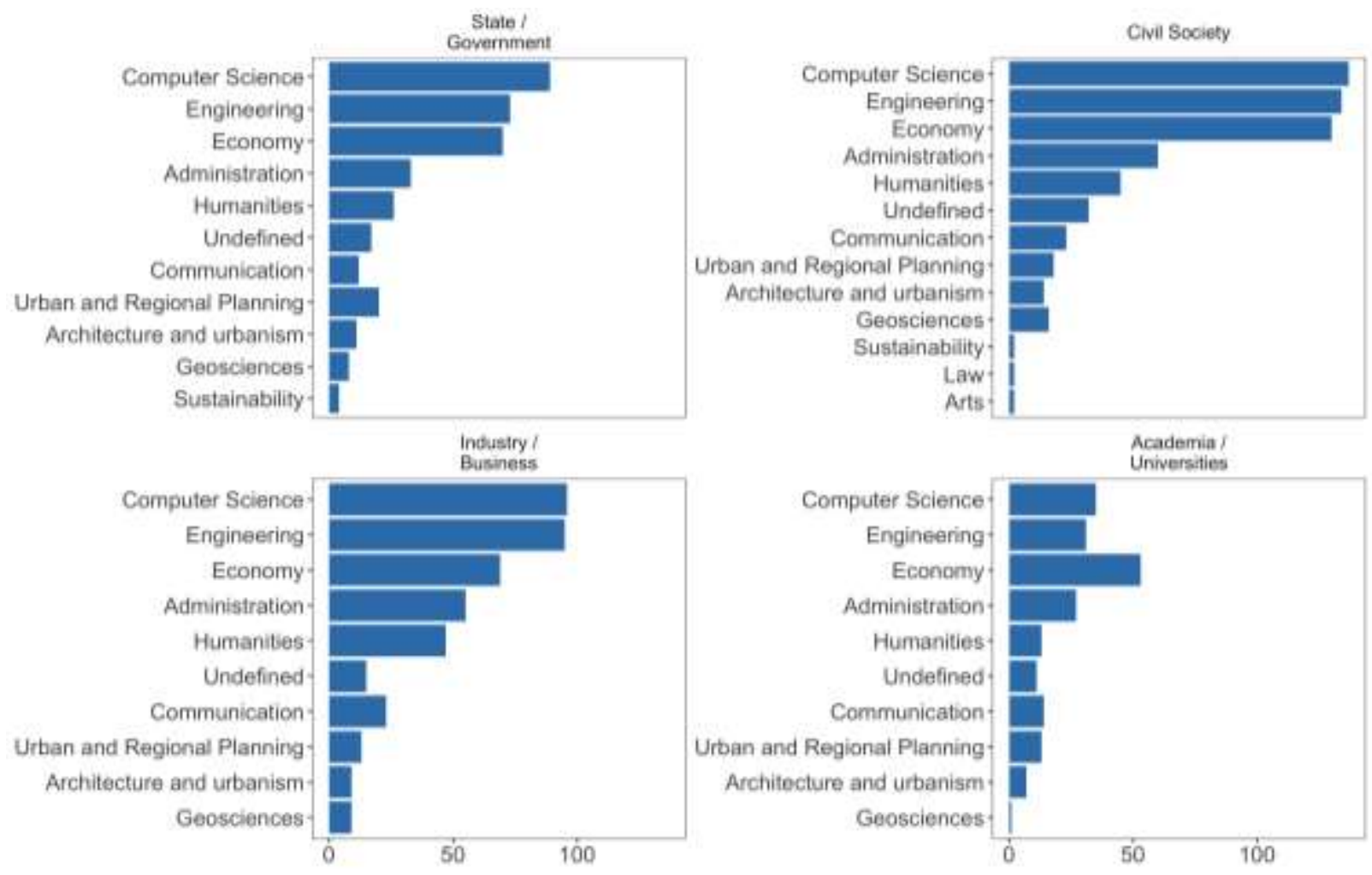

Fonte: Autores.

Com exceção às áreas de sustentabilidade, direito e arte, para as demais áreas do conhecimento, a sociedade civil é o segmento mais reconhecido, seguido pelas empresas e negócios, ficando estado e governo em terceiro lugar. Os demais agrupamentos da hélice quádrupla apresentaram resultados poucos significativos.

Analisamos também a produção de artigos de acordo com a formação acadêmica dos autores e a região geográfica estudada, cujos resultados são apresentados na Figura 8. 
Figura 8. Stakeholders Conforme a Formação dos Autores e Região Geográfica Estudada.

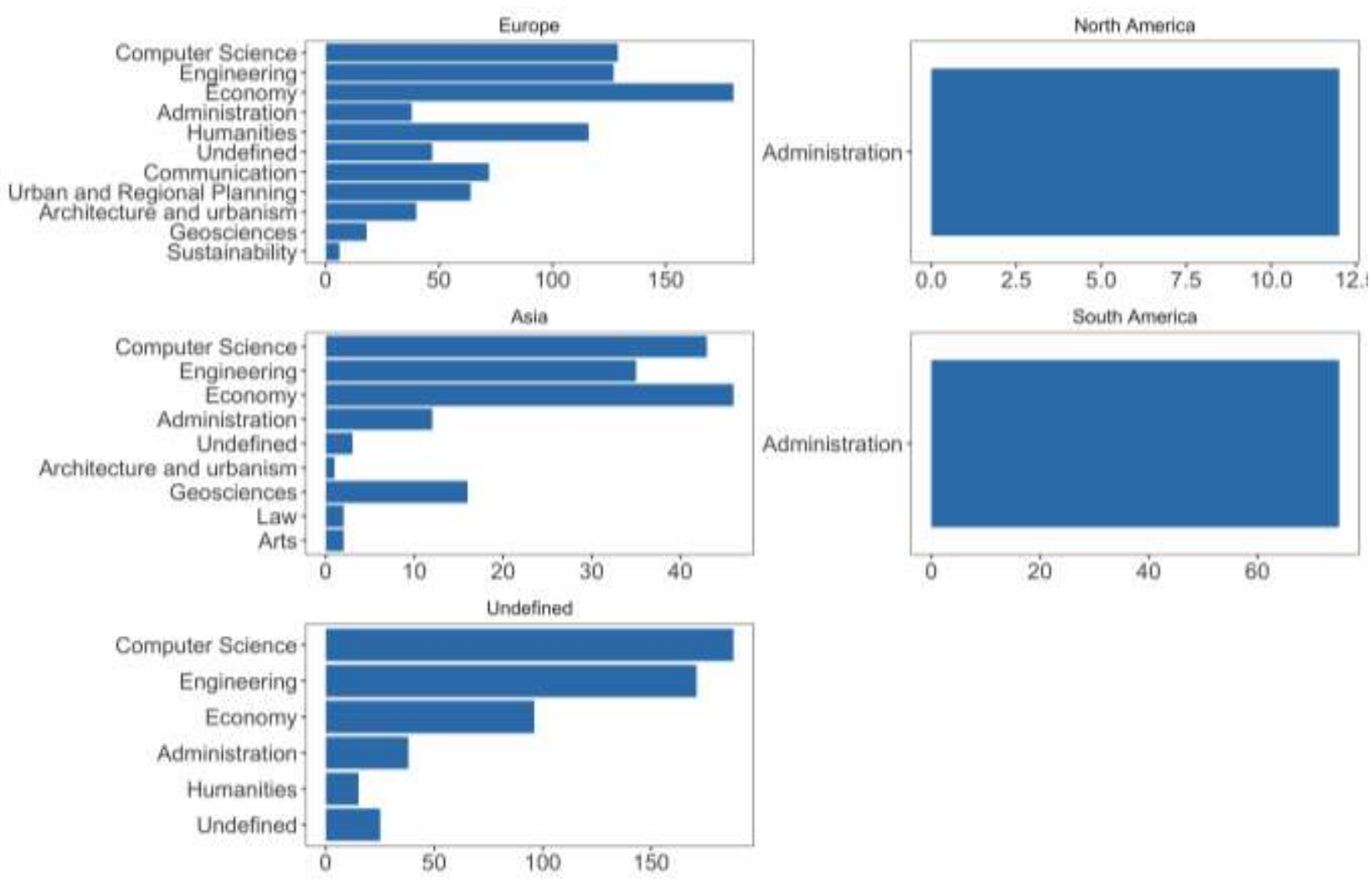

Fonte: Autores.

Temos que, para os autores de área econômica a região mais estudada é a Europa; em segundo lugar temos o agrupamento dos textos que não ofereceram local de estudo; ficando a Ásia em terceiro lugar. Para os autores de Engenharia e Ciência da Computação, os locais indefinidos obtiveram o maior número de citação, seguido pela Europa e, por último, pelo continente asiático. Para a área de Humanas, a Europa vem em primeiro lugar, ficando os locais indefinidos na sequência. Os autores da Administração estudaram a América do Sul de forma majoritária. Já os autores da Comunicação, Planejamento Urbano e Regional, bem como os de Arquitetura e Urbanismo estudaram quase que exclusivamente o continente europeu, enquanto que, os das Geociências trataram da Europa e Ásia.

Conforme a área do conhecimento, os stakeholders mencionados, a partir da hélice quádrupla, observamos que a distribuição dos tipos destas partes interessadas é proporcional em todas as áreas de formação e obedecendo à proporção geral dos stakeholders, sendo a sociedade civil como a mais representada, seguida pela indústria e negócios, por estados e governos e, por último, pela academia / universidades.

Na sequência, passamos à discussão dos resultados.

\section{Discussão}

Não identificamos na literatura nenhuma menção à saliência e aos atributos dos stakeholders das smart cities, sob a ótica de Mitchell et al. (1997), o que indica uma lacuna a ser avaliada ou desenvolvida em estudos futuros.

Em termos individuais, as partes interessadas mais citadas são aquelas que possuem nexo inequívoco e direto com a hélice quádrupla, quais sejam cidadãos e residentes, governo e governantes e indústrias e companhias, respectivamente. 
Registre-se que o segmento relacionado à academia ou universidade aparece em quarto lugar, porém, em patamar relativamente inferior em relação aos dois primeiros colocados. Já para os resultados dos stakeholders agrupados em hélice quádrupla são similares àqueles observados a partir dos stakeholders individualmente, restando a academia mencionada em patamar inferior às demais partes interessadas. Sobre este ponto em especial, discorremos mais adiante.

Em termos geográficos, a Europa foi a região mais estudada. Segundo o Smart City Index editado pelo IMD World Competitiveness Center's Smart City Observatory (2019) 42, dos 102 projetos de cidades inteligentes mapeados ao redor do planeta estão situados na Europa, ou seja, 41,18\% do total. Logo, explicaria o fato de a teoria estar mais direcionada ao estudo dos casos localizados no continente europeu. Anote-se que, segundo Manville et al. (2014), dois terços dos projetos de cidades inteligentes em toda a União Europeia permanecem em planejamento ou em fase de teste piloto; isso significa que o número de iniciativas maduras permanece relativamente baixo, muito embora em quantidade relevante.

Na perspectiva da formação acadêmica dos autores, percebemos baixa participação daqueles oriundos das ciências humanas em contraste com aqueles da área de TIC. 75 dos 82 artigos selecionados foram recentemente publicados - entre 2016 e 2019 - indicando que, muito embora a ciência insista na ampliação do conceito de cidades inteligentes para um sentido menos tecnológico e mais humano, inclusivo, e sustentável (Marrone \& Hammerle, 2018; Myeong et al., 2018; Streitz, 2019), os textos ainda são redigidos por autores formados em TIC, Economia, Engenharia e Administração, de modo absolutamente majoritário, ao encontro, por exemplo do afirmado por Lytras e Visvizi (2018), no sentido de que a pesquisa sobre cidades inteligentes ainda é fortemente baseada na ciência da computação e engenharia, com foco explícito em tecnologia; contrariando a corrente defendida por Bracco, Delfino, Laiolo e Morini (2018) acerca da multidisciplinariedade do campo de pesquisa em smart cities.

De modo geral, temos que a sociedade civil - especialmente cidadãos e moradores - foi a parte interessada mais reconhecida nos textos, independentemente da área de formação dos autores ou da região geográfica do estudo. Tal assertiva contrasta com a corrente da literatura que sustenta que os cidadãos, muito embora reconhecidamente essenciais no contexto das cidades inteligentes (Kummitha \& Crutzen, 2017; Kummitha \& Crutzen, 2019; Marek et al., 2017; Milošević et al., 2019; Myeong et al., 2018; Sarma \& Sunny, 2017), estes tendem a estar sub representados no processo de elaboração e constituição destes espaços (Cardullo \& Kitchin, 2019; Marrone \& Hammerle, 2018). A explicação pode decorrer do fato de que as cidades inteligentes estariam sendo desenvolvidas pelos governos e empresas, enquanto que, os textos acadêmicos pelos profissionais da ciência. Noutras palavras, temos que os cidadãos são menos perceptíveis às lentes dos formuladores de cidades inteligentes e mais perceptíveis aos cientistas e pesquisadores.

Ainda de acordo com a formação acadêmica, do agrupamento dos resultados em hélice quádrupla, consignando sociedade civil, indústria/negócios, estado/governo e academia/universidade como os mais citados. A baixa representatividade deste último grupo de stakeholders vem de encontro ao defendido pela literatura. Nam e Prado (2011), por exemplo, argumentam as instituições de educação como como um dos componentes fundamentais para uma cidade inteligente, enquanto que Praharaj e Han (2019) defendem que uma cidade inteligente deve ser um centro de aprendizagem com uma alta densidade de instituições de ensino superior para garantir o fornecimento de profissionais qualificados. Tal constatação nos leva a crer que, com menor participação de pesquisadores, abre-se maior espaço para governos e empresas de TIC. Em consequência, projetos de cidades inteligentes com apelos predominantemente tecnológicos, mercadológicos e, porque não dizer, meramente políticos ganham impulso (Fernández-Güell at al., 2016; Kummitha \& Crutzen, 2017; Jácomo, 2018). A ampliação do reconhecimento da Academia neste contexto pode ser o fator necessário ao equilíbrio da equação do fator tecnologia versus fatores não tecnológicos. 


\section{Conclusão}

Desenvolvemos este trabalho com objetivo de identificar como a literatura reconhece os stakeholders nas smart cities, quem são, seus atributos e saliência, sob as lentes da formação acadêmica dos respectivos autores e de acordo com a região objeto de estudo dos artigos.

Para tanto utilizamos o método da revisão sistemática da literatura como um processo de investigação primária. A base scopus foi utilizada em busca dos artigos científicos em língua inglesa disponíveis para os anos 2000 a 2019 e que continham nos seus títulos, palavras-chave e resumos as palavras stakeholder(s) e smart city(ies). A base inicial contendo 727 artigos foi reduzida a 82 documentos finais, após executados os filtros e critérios de classificação.

Os resultados evidenciaram a sociedade civil ou os cidadãos como os mais representados, sob todas as perspectivas, seja em termos absolutos, agrupados em hélice quádrupla, a partir da região geográfica ou ainda pela formação acadêmica dos autores. O segmento relacionado à academia ou universidade aparece em quarto lugar. A região geográfica mais estudada foi a Europa com 42 artigos, seguida pelo continente asiático, com 13 estudos. 24 textos não remeteram a algum local específico ou não ofereceram evidências quanto a estes. As formações acadêmicas que mais trataram dos stakeholders nas smart cities foram a ciência da computação com 68 textos, economia com 60 e engenharia 45 indicando que os textos, majoritariamente produzidos por autores pertencentes a estas formações. Incluindo nesta análise a região geográfica estudada, temos que, para os autores de área econômica, os da engenharia e da ciência da computação as regiões mais estudadas são a Europa e a Ásia, sendo que, aqueles textos que não ofereceram local de estudo também foram representativos na amostra para estas formações. Para a área de Humanas, a Europa vem em primeiro lugar, ficando os locais indefinidos na sequência. Os autores da Administração estudaram a América do Sul de forma majoritária. Já os autores da Comunicação, Planejamento Urbano e Regional, bem como os de Arquitetura e Urbanismo estudaram quase que exclusivamente o continente europeu, enquanto que, os das Geociências trataram da Europa e Ásia.

Não identificamos na literatura menção à saliência e aos atributos dos stakeholders das smart cities, indicando lacuna científica a ser estudada em trabalhos futuros.

O segmento de ensino e pesquisa - universidades, escolas técnicas, centros de pesquisa etc. - revelam-se os menos significativos entre os stakeholders citados, o que indica a necessidade de inserção deste grupo como partes interessadas ativas no processo de concepção e implantação cidades inteligentes. Propomos a realização de estudos futuros no sentido de investigar a razão da Academia estar sub representada como stakeholder.

Outra contribuição deste artigo vem no sentindo de que a sociedade civil, embora muito citada, carece de ouvir e ser ouvida efetivamente nestas smart cities, afinal de contas, seriam estes os principais acionistas destas cidades. Caminhos para este desejável cenário precisam ser desenvolvidos.

Como sugestão de trabalhos futuros, propomos ainda o desenvolvimento de uma escala de aferição dos atributos e da saliência das partes interessadas destas smart cities.

\section{Referências}

Axelsson, K., \& Granath, M. (2018). Stakeholders' stake and relation to smartness in smart city development: Insights from a Swedish city planning project. Government Information Quarterly, 35(4), 693-702. https://doi.org/10.1016/j.giq.2018.09.001.

Boucher, Maria B., Rendtorff, \& Jacob D., (2016). Stakeholder theory: A model for strategic management. Paris: Springer International Publishing AG Switzerland.

Bracco, S., Delfino, F., Laiolo, P., \& Morini, A. (2018). Planning \& Open-Air Demonstrating Smart City Sustainable Districts. Sustainability, 10(12), 4636. https://doi.org/10.3390/su10124636.

Cardullo, P., \& Kitchin, R. (2019). Smart urbanism and smart citizenship: The neoliberal logic of 'citizen-focused' smart cities in Europe. Environment and Planning C: Politics and Space, 37(5), 813-830. https://doi.org/10.1177/0263774X18806508. 
Chaturvedi, K., \& Kolbe, T. H. (2019). Towards Establishing Cross-Platform Interoperability for Sensors in Smart Cities. Sensors (Basel, Switzerland), 19(3). https://doi.org/10.3390/s19030562.

Dameri, R. P., \& Benevolo, C. (2016). Governing Smart Cities. Social Science Computer Review, 34(6), 693-707. https://doi.org/10.1177/0894439315611093.

Fernandez-Anez, V., Fernández-Güell, J. M., \& Giffinger, R. (2018). Smart City implementation and discourses: An integrated conceptual model. The case of Vienna. Cities, 78, 4-16. https://doi.org/10.1016/j.cities.2017.12.004.

Freeman, Robert E. (1984). Strategic management. Melbourne: Pitman Publishing Pty. Ltd.

Freudendal-Pedersen, M., Kesselring, S., \& Servou, E. (2019). What is Smart for the Future City? Mobilities and Automation. Sustainability, $11(1), 221$. https://doi.org/10.3390/su11010221.

Hollands, Robert G., (2008). Will the real smart city please stand up? City, 12:3, 303-320. DOI: 10.1080/13604810802479126.

Hosseini, S., Frank, L., Fridgen, G., \& Heger, S. (2018). Do Not Forget About Smart Towns. Business \& Information Systems Engineering, 60(3), $243-257$. https://doi.org/10.1007/s12599-018-0536-2.

Jácomo, L. (2018). Advertising-Cities Face to Smart-Cities. International Journal of E-Planning Research, 7(3), 22-35. https://doi.org/10.4018/IJEPR.2018070102.

Kummitha, R. K. R., \& Crutzen, N. (2017). How do we understand smart cities? An evolutionary perspective. Cities, 67, 43-52. https://doi.org/10.1016/j.cities.2017.04.010.

Kummitha, R. K. R., \& Crutzen, N. (2019). Smart cities and the citizen-driven internet of things: A qualitative inquiry into an emerging smart city. Technological Forecasting and Social Change, 140, 44-53. https://doi.org/10.1016/j.techfore.2018.12.001.

Li, C., Liu, X., Dai, Z., \& Zhao, Z. (2019). Smart City: A Shareable Framework and Its Applications in China. Sustainability, 11(16), 4346. https://doi.org/10.3390/su11164346.

Loet Leydesdorff \& Mark Deakin (2011) The Triple-Helix Model of Smart Cities: A Neo-Evolutionary Perspective. Journal of Urban Technology, 18:2, 5363. DOI: $10.1080 / 10630732.2011 .601111$.

Lombardi P, Giordano S, Farouh H, Yousef, W. (2012) Modelling the smart city performance. Innov Eur J Soc Sci Res 25(2):137-149.

Lytras, M., \& Visvizi, A. (2018). Who Uses Smart City Services and What to Make of It: Toward Interdisciplinary Smart Cities Research. Sustainability, 10(6), 1998. https://doi.org/10.3390/su10061998.

Manville, C., Cochrane, G., Cave, J., Millard, J., Pederson, J. K., Thaarup, R. K., Kotterink, B. (2014). Mapping smart cities in the EU. Directorate General for Internal Policies, Policy Department A: Economic and Scientific Policy. IP/A/ITRE/ST/2013-02, PE 507.480, European Parliament's Committee on Industry, Research and Energy.

Marek, L., Campbell, M., \& Bui, L. (2017). Shaking for innovation: The (re)building of a (smart) city in a post disaster environment. Cities, 63, 41-50. https://doi.org/10.1016/j.cities.2016.12.013.

Marrone, Mauricio \& Hammerle, Mara. (2018). Smart cities: A review and analysis of stakeholders' Literature. Business \& Information Systems Engineering. 60. 10.1007/s12599-018-0535-3.

Meijer, A., \& Bolívar, M. P. R. (2016). Governing the smart city: A review of the literature on smart urban governance. International Review of Administrative Sciences, 82(2), 392-408.

Milošević, M. R., Milošević, D. M., Stević, D. M., \& Stanojević, A. D. (2019). Smart City: Modeling Key Indicators in Serbia Using IT2FS. Sustainability, 11(13), 3536. https://doi.org/10.3390/su11133536.

Mitchell, R., Agle, B., \& Wood, D. (1997). Toward a theory of stakeholder identification and salience: Defining the principle of who and what really counts. The academy of management review, 22(4), 853-886. Retrieved June 17, 2020, from www.jstor.org/stable/259247.

Mosannenzadeh, F., \& Vettoriato, D. (2014). Defining smart city. A conceptual framework based on keyword analysis. TeMa-Journal of Land Use, Mobility and Environment, 6, 683-694.

Myeong, S., Jung, Y., Lee, E. (2018). A Study on determinant factors in smart city development: An analytic hierarchy process analysis. Sustainability, 10 (2606), 1-17. doi:10.3390/su10082606.

Nam, Taewoo \& Pardo, Theresa. (2011). Conceptualizing smart city with dimensions of technology, people, and institutions. ACM International Conference Proceeding Series. 282-291. 10.1145/2037556.2037602.

ONU (2016), New Urban Agenda, Habitat III, available at: http://habitat3.org/the-new-urban-agenda/.

ONU-Habitat (2015), Smart cities, Habitat III, Paper 21, https://unhabitat.org/sites/default/files/2020/09/habitat-iii-issue-paper-3_safer-cities-2.0.pdf acesso em 28 de novembro de 2020 .

Pereira, A. S., Shitsuka, D. M., Pereira, F. J., Shitsuka, R. Metodologia do trabalho científico. UAB / NTE / UFSM, 2018.

Praharaj, S., \& Han, H. (2019). Cutting through the clutter of smart city definitions: A reading into the smart city perceptions in India. City, Culture and Society, 18, 100289. https://doi.org/10.1016/j.ccs.2019.05.005.

Quirino, G., \& Storopoli. J. E., Planos Diretores e Smart Cities (no prelo). 
Research, Society and Development, v. 10, n. 1, e44410111931, 2021

(CC BY 4.0) | ISSN 2525-3409 | DOI: http://dx.doi.org/10.33448/rsd-v10i1.11931

Sarma, S., \& Sunny, S. A. (2017). Civic entrepreneurial ecosystems: Smart city emergence in Kansas City. Business Horizons, 60(6), 843-853. https://doi.org/10.1016/j.bushor.2017.07.010.

Simonofski, A., Vanderose, B., Clarinval, A., \& Snoeck, M. (2018). The Impact of User Participation Methods on E-Government Projects: The Case of La Louvière, Belgium. Media and Communication, 6(4), 175-186. https://doi.org/10.17645/mac.v6i4.1657.

Smart City Index editado pelo IMD World Competitiveness Center's Smart City Observatory (2019), https://www.imd.org/research-knowledge/reports/imdsmart-city-index-2019/ acesso em 28 de novembro de 2020.

Streitz, N. (2019). Beyond 'smart-only' cities: redefining the 'smart-everything' paradigm. Journal of Ambient Intelligence and Humanized Computing, 10(2), 791-812. https://doi.org/10.1007/s12652-018-0824-1.

Tranfield, D., Denyer, D., \& Smart, P. (2003). Towards a methodology for developing evidence-informed management knowledge by means of systematic review. British Journal of Management. 14. 207-222. 10.1111/1467-8551.00375.

UKTI. India's smart city programme: The UK offer to build together. (2015). https://www.gov.uk/government/uploads/system/uploads/attachment_data/file/ 460151/UKTI_-_The_UK_offer_to_build_together_1_.pdf on 16 de dezembro 2020. 